\title{
A PRODUÇÃO DE MATERIAL DIDÁTICO EM AUDIOVISUAL PARA EDUCAÇÃO ESCOLAR INDÍGENA GUARANI MBYA
}

\section{THE PRODUCTION OF TEACHING MATERIAL IN AUDIOVISUAL FOR INDIGENOUS SCHOOL EDUCATION GUARANI MBYA}

Carolina Miranda de Oliveira ${ }^{1}$

Anna Beatriz Albuquerque Vecchia ${ }^{2}$

\begin{abstract}
Resumo
O presente trabalho tem como objetivo retratar como tem sido desenvolvida uma experiência de produção de material didático em audiovisual, elaborado para o suporte pedagógico dos professores das escolas indígenas das aldeias Guarani Mbya. O projeto utiliza uma metodologia participativa, envolvendo no processo de elaboração os professores indígenas e não indígenas e uma ampla inclusão dos alunos Guarani do Ensino Fundamental ( $6^{\circ}$ e $7^{\circ}$ ano) do Colégio Indígena Estadual Guarani Karai Kuery Renda, na aldeia Indígena Sapukai em Angra dos Reis - RJ. Os materiais didáticos destinados para as escolas indígenas, geralmente, carregam um perfil infantilizado e por vezes desassociado da realidade linguística e cultural das aldeias. Nesse sentido, o trabalho aqui mencionado, busca produzir instrumentos pedagógicos adequados para uma escolarização diferenciada, intercultural e bilíngue que fortaleça e preserve a cultura Guarani.
\end{abstract}

Palavras chaves: Escolarização; material didático e indígenas Guarani Mbya.

\begin{abstract}
The objetive of the present article is to portray how has been developed an experience of production of didactic material in audiovisual, elaborated for the pedagogical support of the teachers of the indigenous schools of the villages Mbya Guarani. The project uses a participatory methodology, involving indigenous and non-indigenous teachers in the process of elaboration, as well as the inclusion of Guarani middle school students (6th and 7th grades) of the Karani Kuery Renda Guarani Indigenous State High School in the Sapukai Village in Angra dos Reis - RJ. The teaching materials intended for indigenous schools generally carry an infantile profile and sometimes disassociated with the linguistic and cultural reality of the villages. In this sense, the work mentioned here seeks to produce pedagogical tools suitable for a differentiated, intercultural and bilingual schooling that strengthens and preserves the Guarani culture.
\end{abstract}

Keywords: Schooling; teaching materials and indigenous Guarani Mbya.

\footnotetext{
${ }^{1}$ Formada em Pedagogia pela Universidade Federal Fluminense, integrante do Grupo de pesquisa Investigações Sobre Educação e Diversidades Culturais, mestranda na Universidade de Cádiz, no máster universitario en Investigacion Educativa para el Desarrollo Profesional del Docente. Pesquisas desenvolvidas principalmente no seguinte tema: Educação Escolar Indígena. carolinamiranda@id.uff.br.

${ }^{2}$ Licenciada em Pedagogia pela Universidade Federal Fluminense, situada no Instituto de Educação de Angra dos Reis (IEAR/UFF), Atualmente é Mestranda em Educação no Programa de Pós Graduação em Educação - PPGEdu-UNIRIO. Integrante do Grupo de Pesquisa "Investigações Sobre Educação e Diversidades Culturais" (CNPQ) e do programa "Escolas no Território". bbiavecchia@ gmail.com
} 


\section{INTRODUÇÃO}

A produção do material didático foi realizada através do projeto PROEXT, "Escolarização e Cultura Guarani Mbya Rumo à Universidade"”, aliada ao projeto de pesquisa PIBIC $^{4}$ e ao projeto PIBID $^{5}$. O núcleo da pesquisa é: a) formação de professores não indígenas que atuam no segundo segmento do Colégio Indígena e b) a construção de um currículo diferenciado que potencialize e preserve a cultura e a língua Guarani.

O material didático foi elaborado a partir do processo de reorientação curricular dos professores do Colégio Indígena, posto que esses professores trabalham a partir da Pedagogia de Projetos. Ou seja, eles passam a pensar o currículo a partir de projetos, formando uma rede entre as disciplinas, que deixam de ser centralizadas em conteúdos "próprios" passando a existir uma interdisciplinaridade entre elas.

Os curtas foram produzidos a partir dos eixos pedagógicos: Nhanderekó ${ }^{6}$, Tekoá ${ }^{7}$, Saúde, Artesanato, Segurança Alimentar e Alimentos Tradicionais e Industrializados. Estes temas foram retirados de um eixo temático que resultou num projeto pedagógico, parte da metodologia que será descrita posteriormente. É importante salientar que os Guarani foram os agentes principais durante o processo, desde a elaboração do roteiro, até as filmagens e edição. Descreveremos cada passo, no próximo tópico deste artigo.

O artigo está dividido em duas partes. Na primeira: "Etapas e Construção", descrevemos as etapas da elaboração do material didático. Apontamos como o trabalho foi pensado, organizado, filmando e, posteriormente, editado. Apresentamos também o que originou, o que deu base ao projeto de elaboração do material didático, posto que esse trabalho está atrelado ao processo de reorientação curricular do colégio indígena onde se desenvolveu o projeto.

$\mathrm{Na}$ segunda parte: “A produção de material didático específico para escolas indígenas: uma reflexão" apresentamos uma breve discussão, sobre o material didático e sua produção nas comunidades indígenas. Apoiados em alguns importantes teóricos, problematizamos o assunto, enfatizando a importância de um sério trabalho e envolvimento da comunidade indígena nesse processo, para que assim haja qualidade e coerência no material produzido.

\footnotetext{
${ }^{3}$ Projeto PROEXT - Programa de Extensão Universitária. Iniciado em janeiro de 2016, com 6 bolsistas de licenciatura em Geografia.

${ }^{4}$ PIBIC - Programa Institucional de Bolsas de Iniciação Científica, com uma bolsista de licenciatura em Pedagogia.

${ }^{5}$ PIBID - Programa Institucional de Bolsa de Iniciação à Docência, com 12 bolsistas de licenciatura em Pedagogia.

${ }^{6}$ Nhandereko é o sistema cultural, organizacional e de vida dos Guarani, ou seja, o modo de ser Guarani Mbya.

${ }^{7}$ A Tekoá é o lugar onde os Guarani vivem, sua cultura e espiritualidade.
} 


\section{ETAPAS E CONSTRUÇÃO}

Em 2015, o ensino de Segundo Segmento foi implantado na aldeia Sapakai. Antes, o Colégio Indígena Estadual Guarani Karai Kuery Renda só oferecia o ensino do $1^{\circ}$ a $5^{\circ}$ ano. Para capacitar os professores não indígenas, para atuarem do $6^{\circ}$ ao $9^{\circ}$ ano Guarani, os docentes vêm participando de uma formação continuada, coordenada pelo Professor Domingos Nobre ${ }^{8}$.

A capacitação tem também como objetivo a construção de um currículo diferenciado, intercultural e bilíngue, que fortaleça e preserve a cultura Guarani Mbya. Esse processo está sendo baseado no movimento de reorientação que ocorreu no Brasil, a partir de 1990, especificamente durante a Gestão de Paulo Freire, na Secretaria Municipal de Educação de São Paulo.

Através da formação continuada dos professores, o currículo é pensado a partir de Projetos Pedagógicos (Hernández \& Ventura, 1998), como já mencionado anteriormente. Dessa forma, é possível relacionar os conhecimentos tradicionais e os conhecimentos científicos que são apresentados na escola, de uma forma igual, buscando que esses se complementem e não se anulem.

Para chegar aos projetos pedagógicos, durante a formação continuada, os professores passam por algumas etapas de estudo. A primeira etapa corresponde à sensibilização: os professores discutem a temática de educação diferenciada, as relações étnicoraciais e o papel da escola dentro de uma comunidade indígena, através de oficinas realizadas na comunidade com os pais dos alunos. Os professores começam a conhecer a comunidade nesta primeira etapa.

A segunda etapa consiste nos estudos de cada área. Primeiro é estudada a Epistemologia de cada disciplina/área. A Epistemologia é o caminho que a disciplina percorreu para constar no currículo na forma que conhecemos hoje. Segundo Nobre e França (2017):

Conhecer a epistemologia da área/disciplina permite ao professor reconhecer o processo histórico social de construção da formação (...) que estrutura o campo de conhecimento da disciplina contemporaneamente. (p. 4)

Em seguida, os professores estudam as tendências pedagógicas da sua área. Cada área/disciplina dispõe de tendências liberais e progressistas. O estudo possibilita ao professor entender e ter consciência de como isto reflete em sua prática em sala de aula. Nesse sentido:

\footnotetext{
${ }^{8}$ Professor do IEAR/UFF e coordenador do projeto.
} 
Conhecer as tendências pedagógicas que envolvem a área/disciplina, por sua vez, permite ao professor reconhecer elementos de sua prática pedagógica que se enquadrem ou não nas Pedagogias Liberais ou Progressistas que permeiam o ensino, e fazer opções numa perspectiva autônoma e crítica. (NOBRE \& FRANÇA, 2017, p. 4)

Após terem o conhecimento da epistemologia e das tendências pedagógicas, os professores iniciam os estudos sobre os conceitos integradores e unificadores de cada área. Os conceitos integradores são conhecimentos essenciais que permeiam toda a vida do aluno, diferente dos conteúdos acessórios. Sendo assim:

Estudar os conceitos integradores de cada área/disciplina, por sua vez, permite ao professor distinguir o rol de conhecimentos essenciais daquilo que são apenas conteúdos programáticos de uma grade curricular, portanto acessórios. Conceitos integradores são como a categoria marxista de totalidade no processo de produção dialético do conhecimento, para o Currículo. (...) São exemplos de conceitos unificadores: Espaço, Território e Territorialidades, para a Geografia (...). (NOBRE \& FRANÇA, 2017, p. 4).

E “por fim”, os princípios da Educação Diferenciada. Nesta etapa, os professores estudam as diretrizes curriculares da educação diferenciada, compreendendo os processos históricos de luta e demanda da comunidade, assim como a valorização da cultura.

A terceira etapa consiste em elaborar uma rede temática a partir de um instrumento chamado Diagnóstico Sócio Cultural. Durante a formação, os professores elaboraram um questionário com perguntas sobre a cultura, o lazer, o trabalho e o que os alunos pensam sobre o futuro. Esse questionário foi aplicado pelos professores com cada aluno da escola. Após a aplicação, os resultados foram analisados e foi possível identificar os temas recorrentes que apareceram no questionário, possibilitando a criação de uma rede temática e a escolha dos temas geradores. A partir da rede, foi extraído um bloco temático que possibilita a criação do projeto pedagógico. Com este, os professores podem utilizá-los mensalmente, bimestralmente ou semestralmente, até que se esgotem. (Figura 1).

O projeto pedagógico é o resultado dos conceitos integradores que aparecem nos blocos temáticos. Nele, o professor traça os objetivos e os tópicos de conhecimentos a serem trabalhados, como podemos ver na figura 2. 
A partir dos projetos pedagógicos os roteiros dos vídeos foram pensados para serem utilizados como instrumento pedagógico dos professores, além do fortalecimento da cultura e da língua Guarani.

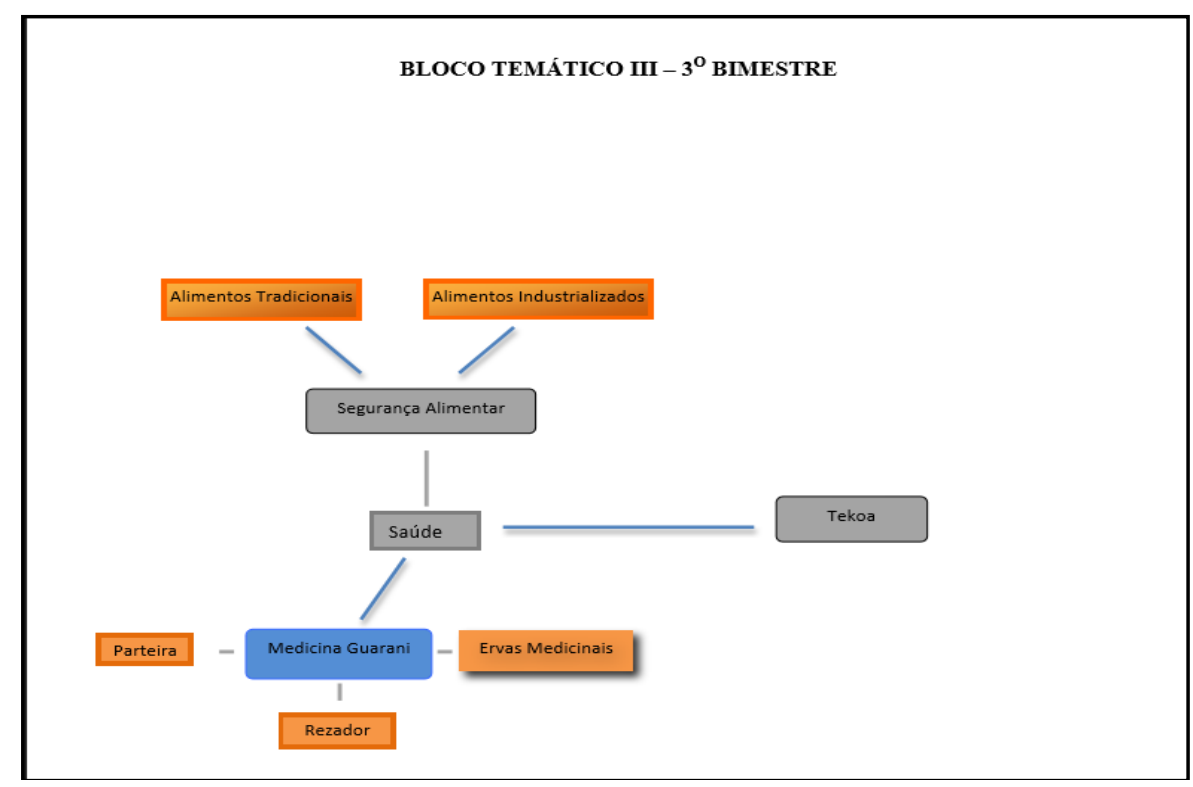

Figura 1: Blocos temáticos que compõem a rede temática do terceiro bimestre, elaborada na formação continuada, por professores do Colégio Indígena Karai Kuery Renda, em 2016, retirado dos relatórios das formações.

\begin{tabular}{|c|c|c|c|}
\hline $\begin{array}{c}\text { Eixos } \\
\text { Temáticos }\end{array}$ & Objetivos Gerais & $\begin{array}{c}\text { Tópicos de } \\
\text { Conhecimento }\end{array}$ & Valores/Atitudes \\
\hline \multicolumn{4}{|l|}{ Opy } \\
\hline \multirow{2}{*}{ Nhandereko } & \multirow{6}{*}{$\begin{array}{l}\text { Contribuir para a valorização da } \\
\text { cultura guarani (saberes tradicionais, } \\
\text { oralidade, história do povo e lingua) }\end{array}$} & \multirow[t]{3}{*}{ Ecologia } & Valorização do bilinguismo; \\
\hline & & & Cooperação; \\
\hline Identidade & & & Trabalho em grupo; \\
\hline Tekoa & & \multirow[b]{2}{*}{ Lugar } & $\begin{array}{c}\text { Respeito aos conhecimentos } \\
\text { tradicionais; }\end{array}$ \\
\hline Artesanato & & & $\begin{array}{c}\text { Conscientização ambiental, } \\
\text { social e política; }\end{array}$ \\
\hline Mobilidade & & \multirow[b]{2}{*}{ Migração } & Cidadania; \\
\hline $\begin{array}{c}\text { Rede de } \\
\text { parentesco }\end{array}$ & \multirow{3}{*}{$\begin{array}{l}\text { Promover a aprendizagem em uma } \\
\text { perspectiva intercultural (bilingue e } \\
\text { diferenciada) }\end{array}$} & & \multirow{5}{*}{$\begin{array}{c}\text { Fortalecimento da identidade } \\
\text { étnica. }\end{array}$} \\
\hline \multirow{4}{*}{ Ecologia } & & Território & \\
\hline & & $\begin{array}{l}\text { Cosmovisão } \\
\text { Guarani }\end{array}$ & \\
\hline & $\begin{array}{c}\text { Reconhecer os conhecimentos } \\
\text { tradicionais como conhecimentos } \\
\text { efetivos. }\end{array}$ & $\begin{array}{l}\text { Identidade } \\
\text { Cultural }\end{array}$ & \\
\hline & $\begin{array}{l}\text { Valorizar a percepção ambiental dos } \\
\text { Guarani. }\end{array}$ & $\begin{array}{c}\text { Linguagem } \\
\text { (comunicação, } \\
\text { expressão e } \\
\text { conhecimento) }\end{array}$ & \\
\hline
\end{tabular}

Figura 2: Projeto pedagógico do primeiro bimestre elaborado na formação continuada, por professores do Colégio Indígena Karai Kuery Renda, em 2016, retirado dos relatórios das formações.

No primeiro semestre de 2016, foi realizada a oficina de audiovisual com os alunos do Colégio Guarani, os professores indígenas e não indígenas do Colégio e os graduandos bolsistas - do IEAR/UFF, ao longo de seis dias. Os envolvidos foram divididos em três grupos 
correspondentes às áreas de: Geografia, Linguagens e Ciências. A orientação sobre o conteúdo dos vídeos foi dada pelos professores do $6^{\circ}$ ao $9^{\circ}$ ano, de cada área.

Durante a primeira etapa, a pré-produção, foi realizada uma orientação sobre o manuseio dos equipamentos, instrução sobre luz, enquadramento, foco, como descarregar os vídeos para o computador e organizá-los, bem como todas as técnicas básicas para a produção de um curta.

$\mathrm{Na}$ segunda etapa os roteiros dos vídeos foram elaborados a partir dos projetos pedagógicos, seguindo as sugestões dos alunos Guarani e dos professores, com a participação de algumas lideranças da aldeia Sapukai. Nesta etapa, a participação dos alunos guarani foi fundamental, dado que eles se sentiram agentes do processo, investigadores de sua própria cultura. Puderam ser ouvidos, tendo suas ideias consideradas. Foram visíveis o forte interesse e envolvimento dos jovens indígenas, a preocupação em captar as imagens mais interessantes e a autonomia em poder filmar o que queriam apresentar nos vídeos.

Durante a terceira etapa, com os grupos divididos por áreas, foram realizadas as filmagens, com base no que foi decidido na elaboração do roteiro. Novamente a participação dos alunos foi fundamental, por terem um olhar sensível ao longo da captação das cenas. Neste passo, os grupos se relacionaram bem entre si, conseguiram atingir os objetivos do roteiro e este processo ocorreu com bastante interação. Foi possível notar que os alunos se divertiram com o trabalho, compreenderam a importância de um material didático específico para sua comunidade de uma forma dinâmica.

A quarta e última etapa foi dedicada à edição dos vídeos. Em cada grupo, um professor Guarani ficou responsável por nos orientar e auxiliar nas traduções. O olhar e a sensibilidade dos jovens Guarani nesta etapa foi essencial. A edição requer um pouco mais de tempo que a filmagem e a elaboração do roteiro. A participação dos integrantes do grupo também foi um fator importante para que a ideia do roteiro permanecesse a mesma até a edição.

Este trabalho resultou na elaboração de seis curtas, divididos em dois DVDs: “Okakuaa (crescimento)”, "Mbya Kokue (roça Mbya)”, “Tembi’u Ete Ja’u (a nossa comida verdadeira)", "Mitã'i Reko (o nosso modo de ser criança)", "Ma'etŷ Reko (nosso jeito de plantar)" e "Tembi’u Porã (comida boa)". É importante salientar que os nomes foram escolhidos pelos Guarani, durante a edição dos vídeos. 


\section{A PRODUÇÃo DE MATERIAL DIDÁTICO ESPECÍfICO PARA ESCOLAS INDÍGENAS: UMA REFLEXÃO}

Falar de produção de material didático para as escolas indígenas nos faz pensar em uma série de questões que devem ser avaliadas e levadas em conta. Não só na escola indígena como em outras realidades culturais, ainda encontramos livros e outros tipos de materiais didáticos que nada têm a ver com a cultura e necessidade do público alvo de determinadas instituições escolares.

Tratando-se das escolas indígenas, podemos salientar que os materiais didáticos destinados são ainda mais precários e escassos. Em diversas comunidades indígenas, há reclamações de professores indígenas do primeiro segmento e professores não indígenas do segundo segmento de ensino, sobre a falta de materiais apropriados. Muitas dessas escolas recebem livros fora de uso das escolas dos juruá ${ }^{9}$, livros esses que fogem da realidade linguística e cultural dos alunos.

Na aldeia Sapukai em Angra dos Reis, onde realizamos o projeto, pudemos presenciar livros espalhados pela escola. Esses são trazidos pela Secretaria Estadual de Educação do Rio de Janeiro - SEEDUC-RJ -, porém não comprados, ou produzidos especificadamente para a comunidade Guarani Mbya, mas são livros que não tinham mais utilidade em escolas de não-indígenas. Essa é uma das críticas dos professores dessa e de outras comunidades indígenas, pois muitas escolas indígenas recebem sempre "o que não serve mais para as escolas de juruá".

Os materiais didáticos produzidos para as escolas indígenas, ainda são insuficientes, no entanto é importante ressaltar que esse cenário tem sofrido alterações, visto que tem crescido o número de materiais didáticos produzidos para atender a necessidade de cada escola indígena. Posto isso, enfatizamos a necessidade da produção de materiais didáticos pautados na real condição linguística e cultural dos alunos.

A elaboração de ferramentas pedagógicas destinadas às comunidades indígenas deve ser realizada de maneira cautelosa, dado que cada etnia possui sua língua e seus costumes. É de extrema importância a presença da língua materna nos materiais didáticos dessas escolas, visto que esse seja um importante canal de valorização das línguas vernáculas e lugar de prestígio da língua na comunidade. Nesse sentido:

Há necessidade de se capacitar os envolvidos em conhecimentos básicos das estruturas linguísticas das línguas indígenas, para a produção de materiais didáticos com mais qualidade e embasamento, pois encontra-se geralmente dificuldade de

\footnotetext{
${ }^{9}$ Juruá significa homem barbudo, não indígena na língua guarani mbya.
} 
reflexão metalinguística na produção do material; daí a questão levantada no debate: Qual o papel do linguista na produção de material didático? (NOBRE, 2015, p. 10).

A produção de material didático para as escolas indígenas de cada etnia precisa ter participação ativa de professores, alunos indígenas e linguistas, para que o trabalho esteja de acordo com a prática cotidiana e linguística da comunidade. A produção desse material precisa estar intrinsecamente ligada ao fortalecimento da língua e da cultura indígena.

A escola pode ser usada como fonte de conhecimento para que os indígenas se apropriem de seus direitos, como também lugar de desvalorização da língua e das tradições. Diante disso é importante que "nesse espaço", a língua materna da comunidade esteja presente no fazer pedagógico da escola, principalmente nos materiais didáticos. Pois:

\footnotetext{
Reconhece-se que "com o desaparecimento de uma língua, desaparece parte da memória da humanidade", "a língua é o veículo da cultura", "sem a língua uma cultura não sobrevive", "a língua é fundada pela e fundante da cultura", mas a maioria das ações se dirige exclusivamente ao "salvamento", ou "revitalização", ou "desenvolvimento" da língua. (MONSERRAT, 2011, p.10)
}

Para que o material produzido tenha relevância e uso dentro da aldeia, faz-se necessário que esse seja produzido de maneira séria e coerente, sem representações de uma realidade que já não existe. Nesse sentido, D’Angelis (2005) afirma que, além de alguns conteúdos não serem relevantes, “(...) o conteúdo trata de um mundo que não existe mais, como se ainda existisse" (p. 23)". Como também:

\begin{abstract}
Há uma produção aligeirada de muitos materiais de qualidade discutível, como cartilhas ou coletânea de textos elaborados em Cursos de Formação ou projetos independentes, sem a devida orientação de natureza linguística, pedagógica e antropológica, assim como observa-se casos em que a publicação, apesar de ter sido produzida em oficinas participativas, tem pouco ou quase nenhuma utilização por parte dos professores na escola. (NOBRE, 2016, p. 11)
\end{abstract}

Esses materiais produzidos de maneira acelerada e sem a devida participação dos indígenas e pesquisadores das línguas indígenas perdem o valor dentro da comunidade. Por possuir informações e características que não coincidem com a realidade cultural e linguística da comunidade, não é considerado um material coerente e de qualidade para o uso pedagógico.

Apoiados em D'Angelis (2008, p. 23), podemos salientar também que, boa parte dos materiais produzidos são destinados ao ensino de $1^{\circ}$ ao $5^{\circ}$ ano, sendo narrativas infantis que não contemplam todos os anos escolares e, também, a comunidade. Segundo o mesmo autor, "se o único foco dos escritores indígenas forem às crianças, muitos temas jamais aflorarão 
ou poderão ser objeto da reflexão escrita, e outros não terão oportunidade de receber um tratamento adulto." (D'ANGELIS, 2008, p. 32)

A tecnologia tem sido usada pelos jovens indígenas para a produção de curtas e longas-metragens. Como exposto nesse artigo, materiais didáticos audiovisuais vêm sendo elaborados, promovendo a qualidade de ensino diferenciado dentro da sala de aula. Esses materiais abordam assuntos pensados pelos indígenas e relativos ao cotidiano e aos diversos problemas enfrentados pela comunidade.

Nesse sentido, a tecnologia cada vez mais acessível, posta à disposição dos jovens indígenas e tem beneficiado a comunidade, os levando a refletirem sobre suas condições sociais e culturais, e sobre toda problemática que envolve a relação com os não índios. Diante disso, podemos enfatizar que "os vídeos e fotografias vêm sendo cada vez mais utilizados como material de reflexão etno-política pelo movimento indígena, como também pela escola indígena, como material didático ou para didático" (NOBRE, 2015, p. 12).

Nessa perspectiva, a produção de materiais audiovisuais descrita neste artigo tem contribuído com a reflexão dos alunos desde as etapas de sua elaboração até a utilização em sala de aula. Nesse processo, os alunos indígenas discutem assuntos relevantes para a comunidade e apreendem a valorizar ainda mais sua cultura.

\section{CONSIDERAÇÕES FINAIS}

Produzir materiais didáticos para todos os anos de escolaridade, para as comunidades indígenas é uma maneira de evidenciar a cultura e a língua dentro da escola. Sendo assim, esse trabalho é de extrema importância e necessidade. Nesse processo, o envolvimento das lideranças indígenas e conhecimento da cultura das comunidades não podem ser ignorados. Nesse processo, os guarani (alunos, professores e lideranças) envolvidos são também pesquisadores de sua própria cultura, refletindo sobre a necessidade de preservá-la e enriquecendo a elaboração do trabalho.

Os materiais didáticos produzidos com a comunidade indígena Guarani Mbya de Angra dos Reis vêm se mostrando um bom recurso pedagógico que possibilita o diálogo entre a sala de aula e os objetivos propostos durante o processo de reorientação curricular. Nesse sentido, os professores discutem as estratégias durante a formação continuada e podem aplicalas na sala de aula, fazendo com que exista assim uma coerência. Além de potencializar a valorização da língua e da cultura Guarani, evidenciando nos curtas produzidos o modo de vida da comunidade. 
Fomentar a elaboração de material didático para as escolas indígenas é uma maneira de garantir o uso da língua guarani que vem sendo ameaçado pela língua dominante. Faz-se necessário que essa produção se estenda para diversos gêneros literários, para que as populações indígenas tenham acesso a leituras em suas línguas nativas. Como já dito anteriormente, essa é uma maneira de fortalecer as línguas indígenas que ainda resistem para futuras gerações.

\section{Referências Bibliográficas}

D’ANGELIS, Wilmar da Rocha. Línguas indígenas precisam de escritores? Linguagem eletramento em foco. Campinas: CEIFIEL/UNICAMP, 2005.

MONSERRAT, Ruth Maria Fonini. Política e Planejamento Lingüístico nas Sociedades Indígenas do Brasil hoje: o Espaço e o Futuro das Línguas Indígenas. In: L. D. B. Grupioni (org.) Formação de Professores Indígenas: repensando trajetórias. Brasília: MEC/SECAD, p. 131-153, 2006.

NOBRE \& FRANÇA, Indira Alves. Uma reorientação curricular pela via das redes temáticas e da pedagogia de projetos. In: MONTEIRO, Lício; NOBRE, Domingos; OLIVEIRA, Mara (Orgs). Caderno Pedagógico para Projetos de Educação Escolar Diferenciada e Intercultural: A produção do Guia Turístico Local nas Escolas Municipais Martin de Sá, na Praia do Sono, e Cajaíba, no Pouso da Cajaíba, Paraty - RJ. Rio de Janeiro: Secretaria Municipal de Educação de Paraty, p. 5-7. 2017.

A Área de Linguagens nas Licenciaturas Interculturais Indígenas:

Questões em Debate. Artigo. I SEALLIN. (no prelo). 2016.

Escolarização Guarani Mbya no Rio de Janeiro: articulando ensino, pesquisa e extensão entre universidade e escola indígena. Montevidéu: XI RAM. 2015.

, (Org.) Proposta Curricular do $6^{\circ}$ ao $9^{\circ}$ ano Guarani Mbya. Colégio Estadual Indígena Guarani Karai Kuery Renda. Angra dos Reis, 2015.

(Org.) Relatórios do Curso de Formação do Programa de Formação

Continuada de Professores do $6^{0}$ ao $9^{\circ}$ Ano Guarani. Colégio Estadual Indígena Guarani Karai Kuery Renda. 2016.

Submetido em: 15/04/2018

Aprovado em: 01/06/2019 